\title{
The Use of Learning Videos to Increase the Activeness of Students on the Content of PPKn Lessons
}

\section{Irnanita Indayah Kusumadewi}

SD Negeri 03 Cikendung

nieta.irna@gmail.com

\section{Article History \\ accepted 01/11/2020}

approved 08/11/2020 published 15/11/2020

\begin{abstract}
The background of the researchers conducting this research is the lack of use of instructional videos as a medium and the low involvement of students in the learning process. The purpose of this study was to increase the activeness of grade IV students by using video lessons on the PPKn lesson content. This research is a classroom action research (PTK) which is conducted in three cycles, each cycle consisting of planning, implementation, observation, and reflection stages. The subjects of this study were the fourth grade students of SD Negeri 03 Cikendung in the 2020/2021 academic year, totaling 20 students. Data collection techniques using observation. The data analysis technique used is the observation data analysis technique. Research shows that the use of instructional videos can increase the activeness of students in the PPKn lesson content, the symbol and meaning of the second Pancasila precepts in class IV SD Negeri 03 Cikendung in the 2020/2021 school year as evidenced by the average percentage of activeness in the first cycle of $60 \%$ to $75 \%$ in cycle II and increased to $80 \%$.
\end{abstract}

Keywords: Video, activeness, student

\begin{abstract}
Abstrak
Latar belakang peneliti melakukan penelitian ini adalah kurangnya pemanfaatan video pembelajaran sebagai media dan rendahnya keterlibatan siswa dalam proses pembelajaran. Tujuan penelitian ini adalah Meningkatkan keaktifan peserta didik kelas IV dengan penggunaan video pembelajaran pada muatan pelajaran PPKn. Penelitian ini merupakan penelitian tindakan kelas (PTK) yang dilaksanakan dalam tiga siklus, setiap siklus terdiri dari tahap perencanaan, pelaksanaan, observasi, dan refleksi. Subjek penelitian ini adalah peserta didik kelas IV SD Negeri 03 Cikendung tahun pelajaran 2020/2021 yang berjumlah 20 peserta didik. Teknik pengumpulan data menggunakan observasi. Teknik analisis data yang digunakan adalah teknik analisis data observasi. Penelitian menunjukkan bahwa penggunaan video pembelajaran dapat meningkatkan keaktifan peserta didik pada muatan pelajaran PPKn materi simbol dan makna pancasila sila kedua di kelas IV SD Negeri 03 Cikendung tahun pelajaran 2020/2021 yang dibuktikan dengan persentase rata-rata keaktifan pada siklus I sebesar $60 \%$ menjadi $75 \%$ pada siklus II dan meningkat menjadi $80 \%$.
\end{abstract}

Kata kunci: video, keaktifan, siswa

Social, Humanities, and Education Studies (SHEs): Conference Series https://jurnal.uns.ac.id/shes

p-ISSN 2620-9284

e-ISSN 2620-9292 


\section{PENDAHULUAN}

Pembelajaran yang didesain secara menarik dan bermakna memberikan pengaruh positif terhadap perkembangan belajar siswa. Hal tersebut dikarenakan dalam pelaksanaan pembelajaran yang didesain secara menarik dan bermakna memberikan kebebasan bagi siswa untuk bereksplorasi mengembangkan segenap potensi yang mereka miliki. Pembelajaran yang diharapkan dapat mengkolaborasi antara kerjasama guru dan siswa dengan menggunakan media yang menarik, sehingga siswa dapat aktif dalam proses pembelajaran dan guru sebagai fasilitator, memfasilitasi segala sesuatu kebutuhan siswa dalam belajar agar siswa mampu menerima pembelajaran dengan maksimal, seperti menggunakan media dalam pembelajaran, yaitu media-media yang menarik bagi siswa.

Penggunaan media dalam pembelajaran di kelas IV oleh guru masih rendah. Guru biasanya mengajarkan materi simbol dan pengamalan pancasila dengan menggunakan metode tugas melalui Whatsapps grup. Kurangnya inisiatif dan kemampuan guru dalam memanfaatkan dan menggunakan media pembelajaran berupa video pembelajaran menjadi salah satu penyebab rendahnya keaktifan siswa dalam proses pembelajaran.

Pemilihan video sebagai media penyebarluasan inovasi selain mampu mengkombinasikan visual dengan audio juga dapat dikemas dengan berbagai bentuk, misalnya menggabungkan antara komunikasi tatap muka dengan komunikasi kelompok, menggunakan teks, audio dan musik. Menurut Sudjana dan Rivai (1992) manfaat media video yaitu: (1) dapat menumbuhkan motivasi; (2) makna pesan akan menjadi lebih jelas sehingga dapat dipahami oleh peserta didik dan memungkinkan terjadinya penguasaan dan pencapaian tujuan penyampaian. Penelitian sejenis yang dilakukan oleh Ika Yatri Lanjar Pratiwi pada penelitian yang berjudul "Peranan Media Video Pembelajaran Dalam Meningkatkan keaktifan Siswa Pada Pembelajaran IPS Di Kelas V SDN Mampang Prapatan 02 Pagi" menunjukkan hasil bahwa pembelajaran IPS melalui peranan media video dapat meningkatkan keaktifan siswa dan berbanding lurus dengan hasil belajar siswa.

Berdasarkan uraian diatas, penulis melakukan penelitian dengan judul Penggunaan Video Pembelajaran Untuk Meningkatan Keaktifan Peserta Didik Pada Muatan Pelajaran PPKn di kelas IV SDN 03 Cikendung tahun pelajaran 2020/2021. Tujuan penelitian ini adalah meningkatkan keaktifan belajar peserta didik kelas IV dengan penggunaan video pembelajaran pada muatan pelajaran PPKn di SDN 03 Cikendung.

\section{METODE}

Penelitian ini merupakan penelitian tindakan kelas (PTK) kolaboratif yang dilaksanakan dalam tiga siklus, setiap siklus terdiri dari tahap perencanaan, pelaksanaan, observasi, dan refleksi. Subjek penelitian ini adalah peserta didik kelas IV SD Negeri 03 Cikendung tahun pelajaran 2020/2021 yang berjumlah 20 peserta didik. Penelitian ini dilaksanakan di SD Negeri 03 Cikendung, Koordinator Wilayah Kecamatan Pulosari, Kabupaten Pemalang pada tanggal 19 Oktober sampai 20 November 2020 ( Pelaksanaan PPL). Data atau informasi yang paling penting untuk dikumpulkan dan dikaji dalam penelitian ini diperoleh dari data kualitatif dari informasi tentang seberapa besar perubahan keaktifan siswa dalam pembelajaran ketika guru mengajar PPKn menggunakan video pembelajaran pada siswa kelas IV SD Negeri 03 Cikendung.

Teknik Pengumpulan data yang digunakan dalam penelitian ini berupa observasi.Penelitian ini menggunakan observasi terstruktur berdasarkan instrumen atau lembar observasi yang telah dibuat. Observer ketika melakukan observasi sambil mengisi lembar observasi yang disediakan dengan cara menilai aspek yang telah dibuat sesuai dengan diskriptor dan mengisi skala rating scale yang terdapat pada 
lembar observasi. Teknik analisis data yang digunakan adalah teknik analisis data observasi meliputi observasi kinerja guru dan aktivitas belajar siswa. Uji validitas data dalam penelitian ini dilakukan dengan triangulasi yang mencakup triangulasi sumber, data, dan waktu. Triangulasi sumber dilakukan dengan cara mengecek data yang diperoleh dari tiga sumber yaitu, peneliti, peserta didik dan dokumen. Triangulasi data yaitu dengan pengecekan kembali data yang diperoleh melalui analisis teknik pengumupulan data yaitu observasi dan dokumentasi. Sedangkan Triangulasi waktu meliputi sebelum, saat, dan setelah dilaksanakan tindakan penelitian.

\section{HASIL DAN PEMBAHASAN}

Berdasarkan analisis hasil penelitian yang telah diuraikan maka pembahasan pada penelitian ini sebagai berikut:

\section{Kinerja guru dalam penggunaan video pembelajaran}

Hasil penelitian menunjukkan peningkatan kinerja dalam penggunaan video pembelajaran yang dilakukan oleh guru. Terlihat pada tabel berikut :

Tabel 1. Peningkatan kinerja guru dalam pembelajaran

\begin{tabular}{|c|c|c|c|}
\hline Kegiatan & Siklus I & Siklus II & Siklus III \\
\hline Melakukan kegiatan apersepsi & 3 & 3 & 3 \\
\hline Menyampaikan tujuan pembelajaran & 3 & 3 & 4 \\
\hline Menayangkan video pembelajaran & 3 & 4 & 4 \\
\hline Menjelaskan materi & 4 & 3 & 3 \\
\hline $\begin{array}{l}\text { Meminta siswa menganalis materi dalam } \\
\text { video }\end{array}$ & 3 & 3 & 3 \\
\hline Menjelaskan cara mengerjakan LKPD & 3 & 3 & 3 \\
\hline Melakukan tanya jawab pada siswa & 3 & 4 & 4 \\
\hline $\begin{array}{l}\text { Menarik kesimpulan dari pembelajaran } \\
\text { yang telah dilakukan }\end{array}$ & 3 & 3 & 3 \\
\hline Memberikan evaluasi pada siswa & 3 & 3 & 3 \\
\hline $\begin{array}{ll}\text { Menjelaskan } & \text { langkah-langkah } \\
\text { mengerjakan evaluasi } & \\
\end{array}$ & 3 & 3 & 3 \\
\hline Rata-rata & 3,1 & 3,2 & 3,3 \\
\hline Persentase & $78 \%$ & $80 \%$ & $83 \%$ \\
\hline
\end{tabular}

Berdasarkan hasil pada tabel diatas rata-rata kinerja guru dalam tiap siklus mengalami peningkatan pada siklus I hasil rata-rata kinerja guru menunjukkan hasil $78 \%$, pada siklus II $80 \%$ dan siiklus III $83 \%$. Dalam hal ini taraf keberhasilan mengajar guru termasuk dalam kategori baik.

2. Keaktifan belajar siswa pada muatan pelajaran PPKn

Hasil penelitian menunjukkan peningkatan keaktifan belajar siswa pada muatan pelajaran PPKn pada materi simbol dan pengamalan pancasila sila kedua dengan penggunaan media video pembelajaran. Terlihat pada tabel berikut :

Tabel 1. Peningkatan keaktifan belajar siswa dengan penggunaan video pembelajaran

\begin{tabular}{ccccccc}
\hline $\begin{array}{c}\text { Rentang rata- } \\
\text { rata skor }\end{array}$ & \multicolumn{2}{c}{ Siklus I } & \multicolumn{2}{c}{ Siklus II } & \multicolumn{2}{c}{ Siklus III } \\
\cline { 2 - 7 } & $\mathbf{f}$ & $\%$ & $\mathbf{f}$ & $\%$ & $\mathbf{f}$ & $\%$ \\
\hline $85 \%-100 \%$ & - & - & 5 & 25 & 7 & 35 \\
\hline $70 \%-84 \%$ & 6 & 30 & 9 & 45 & 13 & 65 \\
\hline $55 \%-69 \%$ & 9 & 45 & 6 & 30 & - & - \\
\hline
\end{tabular}




\begin{tabular}{ccccccc}
\hline $40 \%-54 \%$ & 5 & 25 & - & - & - & - \\
\hline$<39 \%$ & - & - & - & - & - & - \\
\hline Jumlah & 20 & 100 & 20 & 100 & 20 & 100 \\
\hline Rata-rata & 60 & - & $\mathbf{7 5}$ & - & $\mathbf{8 0}$ & - \\
\hline
\end{tabular}

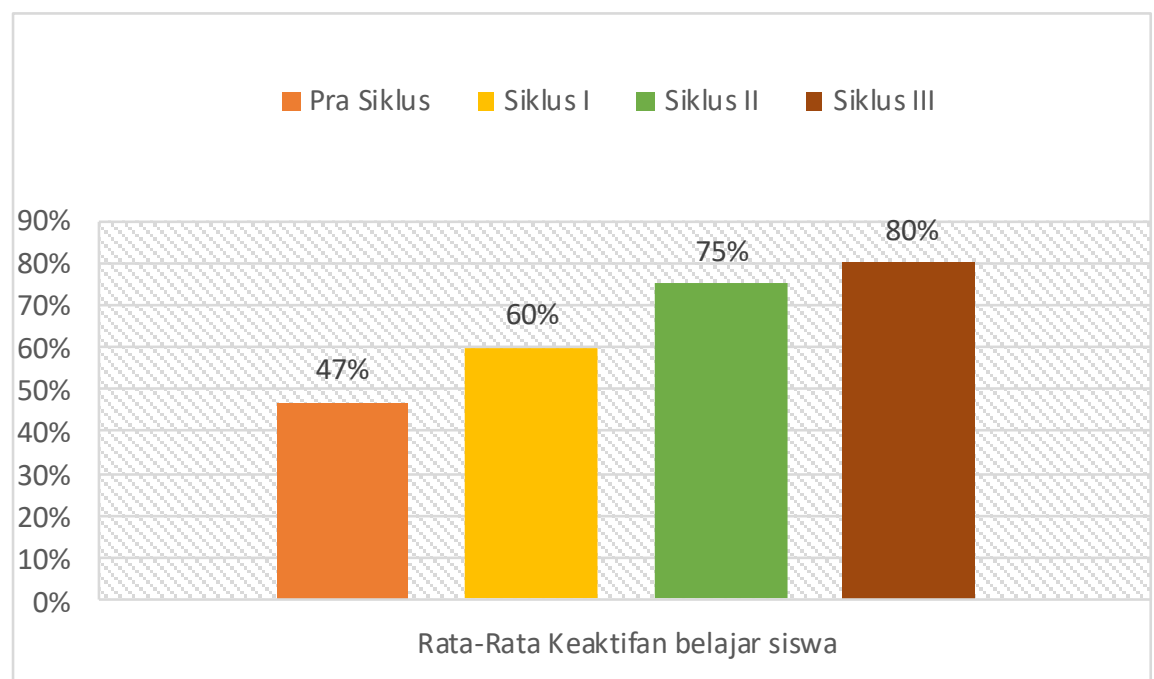

Gambar 1 Grafik perbandingan persentase antara pra-siklus, siklus I, siklus II, dan siklus III

Peningkatan keaktifan belajar peserta didik pada muatan PPKn dengan materi simbol dan pengamalan pancasila sila kedua dengan menggunakan media video pembelajaran dengan instrument lembar observasi. Teknik pengumpulan data keaktifan belajar peserta didik dilakukan disetiap siklus. Penggunaan video pembelajaran dalam muatan PPKn dapat meningkatkan keaktifan belajar peserta didik di kelas IV SD Negeri 3 Cikendung secara signifikan.

Pada hasil observasi sebelumnya tingkat keaktifan belajar siswa dalam muatan pelajaran PPKn mencapai $47 \%$. Setelah dilakukan tindakan, persentase keaktifan belajar pada siklus I meningkat menjadi $60 \%$ dan pada pertemuan kedua menjadi $75 \%$ diikuti pada hasil disiklus ketiga menjadi $80 \%$. Pada siklus I hasil rata-rata keaktifan belum mencapai indikator ketercapain yaitu $75 \%$, pada siklus II dengan hasil rata-rata keaktifan $75 \%$ sebenarnya sudah mencapai ketercapaian target namun untuk hasil yang lebih maksimal peneliti melanjutkannya pada siklus III dengan hasil rata-rata keaktifan belajar siswa naik $5 \%$ dari siklus kedua.

Hasil penelitian secara keseluruhan pada pembelajaran dari siklus I hingga siklus III menunjukkan adanya peningkatan terhadap keaktifan siswa dalam kegiatan pembelajaran. Hal tersebut menunjukkan adanya respon positif dari siswa dalam mengikuti muatan pembelajaran PPKn dengan menggunakan media video pembelajaran. Keaktifan siswa dari sebelum diadakan tindakan rendah.

Berdasarkan analisis hasil observasi keaktifan belajar peserta didik setelah pelaksanaan tindakan, dapat diambil kesimpulan bahwa penggunaan media video pembelajaran dapat meningkatkan keaktifan belajar peserta didik pada muatan PPKn dengan materi simbol dan pengamalan pancasila sila kedua. Penggunaan media video pembelajaran untuk siswa kelas IV SDN 03 Cikendung dapat meningkatkan keaktifan siswa, hal ini dibuktikan bahwa: 
1. Keaktifan siswa kelas IV dalam muatan pelajaran PPKn meningkat, hal ini ditandai dengan adanya peningkatan rata-rata hasil dari observasi.

2. Pelaksanaan pembelajaran yang menggunakan media video pembelajaran membawa dampak positif bagi keaktifan siswa, karena dalam melaksanakan pembelajaran dengan menggunakan media video pembelajaran, pembelajaran akan lebih dapat menarik siswa untuk dapat berperan aktif, melatih bekerja sama, dan dapat menanamkan sikap saling menghargai dengan temannya.

Hal ini sesuai dengan hasil penelitian yang dilakukan membuktikan bahwa penggunaan video pembelajaran dapat meningkatkan keaktifan belajar siswa pada di kelas IV secara signifikan. Peningkatan keaktifan siswa dengan menggunakan media video pembelajaran sejalan dengan teori Gagne dan Briggs, dan Paul D. Dierich (Martinis Yamin 2007) yang mengatakan bahwa untuk meningkatkan keaktifan salah satunya dengan memunculkan aktivitas, partisipasi siswa dalam kegiatan pembelajaran dan kegiatan untuk memunculkan keaktifan dalam pembelajaran dapat dilakukan dengan beberapa hal salah satunya dengan melihat video pembelajaran.

\section{SIMPULAN}

Berdasarkan hasil penelitian dan uraian pembahasan maka dapat diambil simpulan sebagai berikut dari hasil penelitian tindakan kelas yang dilakukan secara kolaboratif dan dilaksanakan dalam tiga siklus dapat disimpulkan bahwa, keaktifan siswa pada pembelajaran PPKn di SD $\mathrm{N} 03$ Cikendung dapat ditingkatkan dengan menggunakan Video pembelajaran. Pembelajaran PPKn menjadi lebih menarik bagi siswa dan dapat memotivasi semangat siswa dalam mengikuti pembelajaran PPKn. Peningkatan keaktifan siswa tersebut terbukti dari hasil rata-rata observasi siswa setelah dilakukan tindakan pada siklus I, siklus II dan siklus III. Dengan menggunakan media video pembelajaran dalam pembelajaran PPKn diperoleh rata-rata hasil siklus I mencapai $60 \%$ (kategori cukup), pada siklus II mencapai $75 \%$ dan pada siklus III naik mencapai $80 \%$ (kategori tinggi).

Peningkatan maksimal ini karena adanya media video pembelajaran yang sebelumnya sederhana, pada siklus II dan siklus III video pembelajaran divariasikan dengan penambahan gambar-gambar contoh pengamalan pancasila. Dalam siklus III, guru dalam berinteraksi dengan siswa juga sangat baik. Guru selalu memberikan motivasi kepada siswa sehingga siswa dapat percaya diri dalam kegiatan pembelajaran.

Berdasarkan kesimpulan hasil penelitian, peneliti menyarankan guru dapat melaksanakan muatan pelajaran PPKn di kelas dengan menggunakan media video pembelajaran untuk meningkatkan keaktifan siswa pada materi simbol dan pengamalan pancasila sila kedua. Secara khusus saran diberikan kepada pihak-pihak diantaranya kepala sekolah, guru, dan dinas pendidikan. Bagi Sekolah hendaknya lebih mengoptimalkan pengeluaran Rencana Anggaran Belanja Sekolah, untuk pembelian media pembelajaran atau alat peraga, sehingga guru bisa menggunakan media pembelajaran dengan optimal karena sudah tersedia di sekolah. Bagi guru hendaknya lebih aktif memfasilitasi kebutuhan siswa salah satunya dengan menyediakan media pembelajaran yang menarik bagi siswa agar siswa tidak jenuh.

\section{DAFTAR PUSTAKA}

Arikunto, Suharsimi. (2006). Penelitiian Tindakan Kelas. Jakarta : Bumi Aksara

Arsyad, Azhar. (2003). Media Pembelajaran. Jakarta: Raja Grafindo Persada. 
Basyiruddin Usman. (2002). Media Pendidikan. Jakarta: Ciputat Press

Daryanto. (2011). Media Pembelajaran. Bandung: Satu Nusa

Fathurrohman \& Wuryandani, wury. 2010. Pembelajaran PKn di Sekolah Dasar Untuk $P G S D$ dan Guru SD. Yogyakarta: Nuha Litera.

Mulyatiningsih, Endang. 2011. Metode Penelitian Terapan Bidang Pendidikan. Bandung: Alfabeta.

Sadiman, Arief S, dkk, 2012. Media Pendidikan Pengertian, Pengembangan, dan Pemanfaatannya. Pustekom Dikbud dan RajaGrafindo Persada. Jakarta

Wibawa, Basuki dan Farida Mukti. 2001. Media Pengajaran. Bandung: CV. Maulana.

Winataputra, Udin. S. 2009. Pembelajaran PKn di SD. Jakarta: Universitas Terbuka. 